\title{
Systemic Lupus Erythematosus Nephritis Class III
}

National Cancer Institute

\section{Source}

National Cancer Institute. Systemic Lupus Erythematosus Nephritis Class III. NCI

Thesaurus. Code C123117.

Systemic lupus erythematosus nephritis with active of inactive focal, segmental or global endo- or extracapillary glomerulonephritis involving less than $50 \%$ of all glomeruli, typically with focal subendothelial immune deposits with or without mesang ial alterations. (Weening, Jan J. et al. (2004). The Classification of Glomerulonephritis in Systemic Lupus Erythematosus Revisited. Journal of the American Society of Nephrology 15(2), 241-50.) 